\title{
Selective IgM Deficiency with T Cell Defects and Mycobacterium Avium Complex (MAC) Infection
}

\author{
Sudhir Gupta*, Sudhanshu Agrawal and Sastry Gollapudi \\ Cellular Immunology Laboratory, Division of Basic and Clinical Immunology, University of California, Irvine, CA \\ 92697, USA
}

\begin{abstract}
Primary selective IgM deficiency in adults is associated with normal $\mathrm{T}$ cell function, and patients clinically manifest with recurrent pyogenic bacterial infections. In this study, we present three patients with selective IgM deficiency with significant defects in T cells and NK cell cytotoxicity, and Mycobacterial avium intracellulare (MAC) infection. $\mathrm{T}$ cell defect is characterized by markedly reduced numbers of $\mathrm{T}$ cells and $\mathrm{T}$ cell subsets, decreased $\mathrm{T}$ cell proliferative responses to mitogens and antigens, including PPD, and significantly decreased production of IFN- $\gamma$; however, expression of IFN- $\gamma$ receptors is normal. We propose that selective IgM deficiency with significant $\mathrm{T}$ cell functional defects might represent a distinct clinical entity, which is associated with increased susceptibility to MAC infection.
\end{abstract}

Keywords: IFN- $\gamma$, IgM deficiency, T cell deficiency, NK cytotoxicity.

\section{INTRODUCTION}

Selective IgM deficiency is a rare form of primary immunodeficiency that has been reported to have a prevalence ranging from $0.03 \%$ to $0.3 \%$ [1]. Selective $\operatorname{IgM}$ deficiency can be asymptomatic or may symptomatically present with infections from encapsulated bacteria and viruses, some of which can be serious and even lifethreatening infections varying from pneumonia to septicemia and meningitis [2-4]. Hobbs et al., [3] first described selective IgM deficiency in 2 children with fulminant meningococcus septicemia. We described an adult patient with primary selective IgM deficiency who presented with disseminated sepsis and invasive aspergilosis [5].

Selective IgM may occur as a primary or secondary condition. Secondary selective $\operatorname{IgM}$ deficiency is often associated with malignancy or immunosuppressive therapy [6-9]. Selective IgM deficiency has been reported to be associated with autoimmunity and autoimmune diseases [10, 11]; however, it remains unclear whether autoimmunity is primary or secondary to selective $\operatorname{IgM}$ deficiency, since patients with primary immunodeficiencies are more prone to autoimmunity and autoimmune diseases $[12,13]$. Furthermore, mice deficient in IgM develop spontaneous autoimmunity, including anti-DNA and immune complex nephritis [14], suggesting that autoimmunity may be secondary to selective IgM deficiency.

Recently, we reported that adult patients with selective primary IgM deficiency and recurrent pyogenic bacterial infections display relatively normal $\mathrm{T}$ cell functions [15]. Here we report an extensive immunological analysis of three patients with primary selective IgM deficiency who presented

*Address correspondence to this author at the Medical Sciences I, C-240, University of California at Irvine, Irvine, CA 92-697, USA; Tel: (949) 8245818; Fax: (949) 824-4362; E-mail: sgupta@uci.edu with atypical mycobacterial infection, and had significant $\mathrm{T}$ cell defects. Whether they represent a distinct disease entity remains to be determined.

Case 1: A 48 years young woman was admitted with fever, productive cough and dyspnea. A chest x-ray revealed right upper lobe infiltrates. Sputum was $4+$ positive for AFB and blood culture revealed Mycobacterium avium intracellulare. Past history is significant for multiple group B streptococcus, vancomycin-resistant enterococcus, and gram+ sepsis, and endocarditis. Serum IgM ranged between 19$23 \mathrm{mg} / \mathrm{dl}$; IgA, IgG, and IgG subclasses were normal. Specific IgG antibody response to pneumococcus polysaccharides following Pneumovax-23 immunization was significantly reduced (antibodies were less than $1 \mathrm{IU} / \mathrm{ml}$, which are considered unprotective). Initially autoimmune work-up was unremarkable. However, later she developed anemia and autoimmune thrombocytopenia, and breast cancer. This patient died of breast cancer.

Case 2: A 56 years young women who developed coronary artery disease, and on routine work up was found to have pulmonary nodule. A biopsy and culture revealed Mycobacterium avium intracellulare. Though the patient was asymptomatic, she was treated with anti-mycobacterial agents. Repeated immunoglobulin analyses revealed low serum IgM levels ranging between $15-19 \mathrm{mg} / \mathrm{dl}$. Immunoglobulin A, G, and $G$ subclasses were normal. Specific $\mathrm{IgG}$ antibody response to pneumococcus polysaccharides following Pneumovax-23 immunization were $<1 \mathrm{IU} / \mathrm{ml}$ (unprotective). Autoimmune work-up for systemic autoimmune diseases was unremarkable. She remained asymptomatic.

Case 3: A 70 years young man initially presented with recurrent upper respiratory tract infections. Immunological investigation revealed low serum IgM ranging between 23$27 \mathrm{mg} / \mathrm{dl}$, and poor specific antibody response to pneumococcus polysaccharides following Pneumovax-23 immunization. He was treated with intravenous 
immunoglobulin at monthly interval, and remained infectionfree for almost 2 years. He then developed a chronic productive cough for which he was investigated, and sputum cultures revealed Mycobacterium avium intracellulare.

None of these patients had any risk factors for HIV, including history of blood transfusion, or use of elicit intravenous drugs. Male patient is married and monogamous. Therefore, HIV was not tested. There was no history of childhood infections, relatives with opportunistic infections or Immunodeficiencies, and our patients were of middle and old aged. Therefore, our patients are unlikely to have partial deficiency of adenosine deaminase (ADA). Therefore, no ADA analysis was performed.

All three patients underwent extensive immunological analyses.

\section{MATERIALS AND METHODS}

Peripheral blood mononuclear cells (MNCs) were isolated from the blood of healthy young subjects and patients by Ficoll-hypaque density gradient. Protocol was approved by Human Subject Committee of the Institutional Review Board, University of California, Irvine

\section{METHODS}

\section{Immunophenotypical Analysis of Lymphocytes}

Twenty $\mu 1$ of the following antibodies were incubated with $100 \mu 1$ of whole blood: CD3-FITC with CD4-PE, CD8-PE, CD19-PE, or CD16/CD56-PE. $\mathrm{IgG}_{1}$-FITC and $\mathrm{IgG}_{2 \mathrm{a}} \mathrm{PE}$ were used as isotype controls (BD Biosciences, Becton-Dickinson, San Jose, CA). Whole blood was lysed with IMK-lymphocyte lysing solution (BD Biosciences, Becton Dickinson, San Jose, CA) for 15 minutes and the lymphocytes were fixed with $1 \%$ paraformaldehyde solution. Flow cytometry acquisition was performed on a FACSCalibur flow cytometer (BD Biosciences, Becton Dickinson, San Jose, CA). Data were analyzed with Simulset software and the percentage and absolute numbers of lymphocytes were determined.

\section{Determination of Lymphocyte Proliferation}

Lymphocyte proliferation was performed with peripheral blood mononuclear cells isolated by Ficoll-Hypaque density gradient centrifugation. Mononuclear cells $\left(2 \times 10^{5} /\right.$ well $)$ were cultured in triplicate in round bottom tissue culture plates at $37^{\circ} \mathrm{C}$ in the presence or absence of optimal concentrations of phytohemagglutinin (PHA), concanavalin (ConA), pokeweed mitogen (PWM), Candida albicans, tetanus, mumps, and PPD. Mitogen and antigen plates were incubated at $37^{\circ} \mathrm{C}$ for 3 days and 6 days, respectively. Twenty-four hours prior to termination of culture, $1 \mu \mathrm{Ci}$ of ${ }^{3} \mathrm{H}$-thymidine was added to each well. Cultures were harvested and ${ }^{3} \mathrm{H}$-thymidine incorporation into DNA was determined by a scintillation spectrometer. Data are expressed as net counts/ min after subtracting background counts from experimental counts.

\section{Measurement of Cytokines}

Cytokine secretion was measured in PBMCs by ELISA assay. Cells were activated by $\mathrm{CD} 3 / 28$ for $48 \mathrm{hrs}$. Supernatants were collected and stored at $-20^{\circ} \mathrm{C}$ until assayed for detection of cytokines by ELISA (ELISA kits from BD Pharmingen, San Jose, California) assayed as per BD Pharmingen protocol.
Natural killer (NK) Activity: Natural killer cell mediated cytotoxicity was determined by a non-radioactive cytotoxic assay using flow cytometry. Briefly, K562 tumor target cells $\left(2 \times 10^{4}\right.$ cells) were labeled with the cell tracking dye CFDA SE (Carboxyfluorescein diacetate, succinimidyl ester, laser emission, FL1, Molecular probes, Eugene OR) and were cultured with peripheral blood mononuclear cells at an effector: target ratio of 12.5:1, 25:1, 50:1 and 100:1. After 4 hour incubation at $37{ }^{\circ} \mathrm{C}$, live dead stain 7- aminoactinomycin D (7AAD, Laser emission FL3 channel, BD Biosciences,) was added to measure target cell death. 7AAD only enters membrane-compromised cells and stains dead cells. For each sample, data from 10,000 target cells were collected by FACScalibur flow cytometer and analyzed. During analysis an electronic gate is placed on CFSE-labeled target cells and percent dead (7AAD+ve cells) were determined. A sample containing only target cells was used to determine background lysis and was subtracted from actual lysis for each sample containing effector and target cells. Results are expressed in lytic units (LU) in $10^{7}$ effector cells. A lytic unit is defined as the number of effector cells required to lyse $20 \%$ of target cells and LU for $10^{7}$ effector cells is calculated using the following formula.

$$
\begin{aligned}
& \text { LU } 110^{7} \text { effectors }=\frac{10^{7}}{(\mathrm{~T}) \mathrm{XP}} \\
& \mathrm{T}=\text { number of target cells }\left(2 \times 10^{4}\right) \\
& \mathrm{P}=\text { Reference lysis level }(20 \%) \\
& \mathrm{XP}=\text { Effector: target ratio required to lyse } 20 \% \text { of the targets. }
\end{aligned}
$$

\section{Measurement of Oxidative Burst}

Oxidative burst (production of reactive oxygen species) was determined by utilizing oxidation -dependent fluorescence of dye dihydrorhodamine 123 (DHR123). Briefly, $10 \mu \mathrm{M}$ cell permeable DHR123 (Invitrogen, San Diego, CA) was added to heparinized whole blood and incubated in a $37^{\circ} \mathrm{C}$ water bath for 15 minutes. Dye loaded blood cells were stimulated with PMA $(0.5 \mu \mathrm{g} / \mathrm{ml})$ for 15 minutes, and the increase in fluorescence associated with oxidation of DHR123 was analyzed on FACScalibur using cell quest software. During analysis an electronic gate was placed on neutrophils or monocytes and the mean fluorescence channel number (MFC\#) was recorded. Cells incubated in the absence of PMA were served as controls for determination of basal level of oxidative burst.

\section{Phagocytosis}

Flow cytometric assay was used to determine phagocytosis of FITC-labeled bacteria by human neutrophils and monocytes. Briefly, $100 \mu \mathrm{l}$ whole blood was dispensed into polystyrene tubes. One microliter of FITC-labeled E. coli (Invitrogen, San Diego, CA) solution $\left(10^{9} / \mathrm{ml}\right)$ was added to each tube and incubated at $37^{\circ} \mathrm{C}$ in an agitating water bath. Cells incubated on ice served as specificity control. After 15 minutes incubation, red blood cells were lysed with FACS lysing solution, washed with ice cold phosphate buffered solution, and resuspended in PBS. Prior to FACS analysis, Trypan blue solution (04\%) was added to each tube to quench FITC fluorescence of unbound and membrane bound E. coli. Phagocytosis of bacteria was determined by measuring green 
fluorescence at $525 \mathrm{~nm}$ on the FACS Calibur flow cytometer, using $488 \mathrm{~mm}$ excitation and analyzed using cell quest software. Instrument settings were adjusted based on the expected fluorescence for normal neutrophils and monocytes without $E$. coli. Results are expressed as \% phagocytosis.

\section{RESULTS}

All immunological data are shown in Table 1.

Lymphocyte subsets: All three patients had low CD4+ T cell numbers and decreased $\mathrm{CD} 4+/ \mathrm{CD} 8+\mathrm{T}$ cell ratio. The deficiency of $\mathrm{CD} 3+, \mathrm{CD} 4+\mathrm{T}$ cells, and NK cells was most severe in patient 1 , who developed disseminated MAC infection and later developed autoimmune thrombocytopenia and breast cancer. B cells were markedly decreased in patient \#2.
Lymphocyte Proliferative responses: Patients with selective IgM deficiency have been reported to have normal proliferative response to mitogens and antigens [15]. Proliferative response to mitogens (PHA, ConA, PWM) and antigens (mumps, Candida albicans, and tetanus toxoid) were markedly decreased in all three patients; none of the patients responded to purified protein derivative (PPD). Proliferative responses to mitogens and antigens were most severely depressed in patient 1 .

Natural killer cytotoxicity: Natural killer cytotoxicity at effector: target ratio of 100:1 and lytic units was decreased in all three patients; however, cytotoxicity was severely impaired in patient \# 1 .

Phagocytosis and Oxidative burst: Bacterial (E. coli) phagocytosis was by PMN and monocytes were decreased in

Table 1. Immunological Profile of Patients with Selective IgM Deficiency and MAC Infection

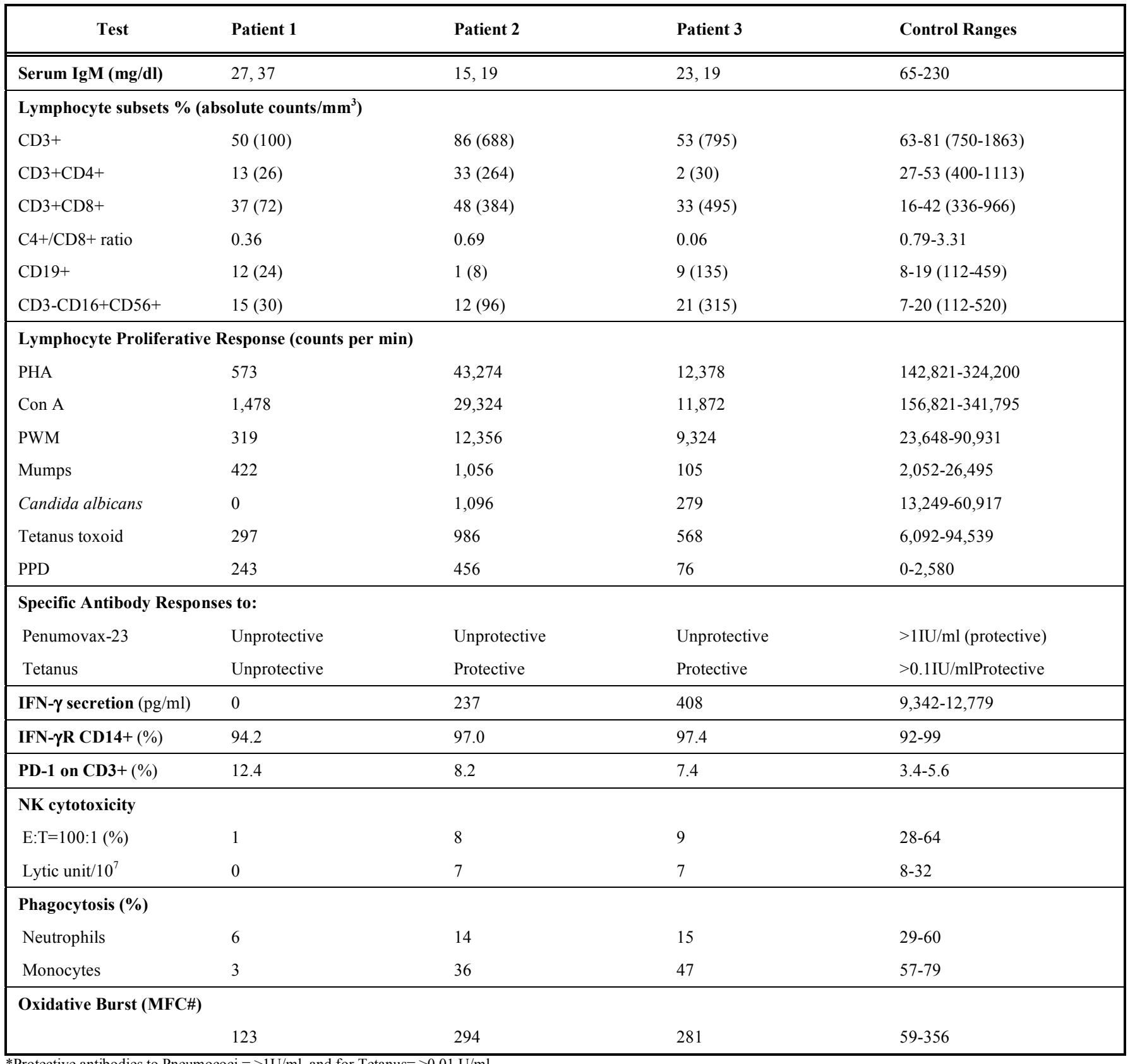

*Protective antibodies to Pneumococi $=>1 \mathrm{U} / \mathrm{ml}$, and for Tetanus $=>0.01 \mathrm{U} / \mathrm{ml}$. 
all three patients; however, reactive oxygen species generation was normal.

Interferon $\gamma$ secretion and IFN- $\gamma \mathrm{R}$ expression: Since IFN- $\gamma$ plays an important role in defense against mycobacterial infections [16-19] and mutation of IFN- $\gamma \mathrm{R}$ is associated with mycobacterial infection [19], we examined production of IFN$\gamma$ by $\mathrm{T}$ cells and expression of IFN- $\gamma \mathrm{R}$ on monocytes. Peripheral blood MNC were stimulated by anti-CD3 plus antiCD28 for 48 hours and IFN- $\gamma$ secretion was measured by ELISA assay. IFN- $\gamma \mathrm{R}$ expression on CD14+ monocytes was analyzed by dual color flow cytometry. IFN- $\gamma$ secretion was markedly reduced in all three patients, almost no IFN- $\gamma$ secretion was observed in the patient with disseminated MAC infection (patient 1); however, IFN- $\gamma \mathrm{R}$ expression was normal. Since IFN- $\gamma$ secretion was measured on MNC it is possible that decreased IFN- $\gamma$ secretion is due to decreased number of $\mathrm{T}$ cells

PD-1 expression: Since PD-1 and PD-1L play a role in immune response and over expression is associated with $\mathrm{T}$ cell anergy and tolerance [20], we examined the expression of PD1on CD $3+\mathrm{T}$ cells by dual color flow cytometry. No increased expression of PD-1 on T cells was observed.

\section{DISCUSSION}

Primary selective IgM deficiency in adults is associated predominantly with pyogenic infections. The most common presentation is recurrent and chronic upper and lower respiratory tract infections and sepsis [2-5, 23]. B cells, T cells and $\mathrm{T}$ cell subsets, and NK cells are normal [5, 15, 21-24]. T cell functions are normal $[5,15]$. Innate immune functions are normal [15]. Specific antibody response to pneumococci is impaired in 50\% of symptomatic cases [15].

Though levels of $\operatorname{IgG}$ and $\operatorname{IgG}$ subclasses are normal, decreased specific $\operatorname{IgG}$ antibody response to tetanus toxoid and/or pneumococcal polysaccharides have been reported [5, 15, 25]. Guill et al., [25] also reported decreased IgM response to immunization with $\varphi$ X174 in children with selective IgM deficiency. The proportions and numbers of $\mathrm{CD} 4+, \mathrm{CD} 8+\mathrm{T}$ cells and $\mathrm{CD} 4+/ \mathrm{CD} 8+\mathrm{T}$ cell ratios have been reported to be normal, low, or high $[5,11,15,22-25]$. In our patients, a severe $\mathrm{T}$ cells and CD4+ lymphopenia, and abnormally low CD4+/CD8+ ratios were observed, and patient with disseminated MAC infection appears to have most severe lymphopenia. Furthermore, severely impaired lymphocyte proliferative responses to mitogens and antigens, including PPD, were observed. T cell functions in patients with selective IgM deficiency with pyogenic bacterial infections are generally normal $[5,15]$. Two of three patients had low numbers of CD19+ B cells, and the most severe deficiency of B cells was observed in asymptomatic patient (Patient 2). Therefore, B cell deficiency does not appear to play a role in increased susceptibility to MAC infection. Low number of B cells has also been reported in patients with selective IgM deficiency with normal $\mathrm{T}$ cell functions and without mycobacterial infection [15]. NK cell activity was impaired in all three subjects; however, NK cell activity was markedly compromised in patient with disseminated MAC (Patient 1). The bacterial phagocytosis by both neutrophils and monocytes was impaired in all three patients; however, reactive oxygen species (ROS) generation following stimulation by PMA was normal. It is possible that ROS generation following phagocytosis of bacteria may be impaired.

Host control of mycobacterial infection depends on IFN- $\gamma$ produced by $\mathrm{CD} 4+\mathrm{Th} 1$ cells that activates macrophages to kill intracellular bacteria [26]. IFN- $\gamma$ deficiency has been considered to be a major factor in the etiopathogenesis for MAC infections [27]. IL-12 plays an important role in defense against mycobacterial infections by inducing production of IFN- $\gamma$, which then binds to IFN- $\gamma \mathrm{R}$ on macrophages to activate them to eliminate mycobacterial [28-30]. Our patients also had impaired IFN- $\gamma$ production and most severe reduction was observed in the patient \# 1 with disseminated MAC infection. However, IFN- $\gamma \mathrm{R}$ expression was normal. Therefore, it is possible that decreased IL-12 production by dendritic cells or decreased expression of IL-12R on $\mathrm{T}$ cells might be responsible for decreased IFN- $\gamma$ production in our patients. This possibility remains to be investigated.

Severe CD4+ $\mathrm{T}$ cell lymphopenia is also observed in idiopathic CD4+ T lymphopenia (ICL; 31-35). It is possible that our patients might be ICL and selective IgM deficiency is a co-incidental finding. However, it appears unlikely since ICL patients have either normal level of immunoglobulins [31-33], low IgG and IgA [34], or increased IgA [34], but IgM levels are normal. Furthermore, MAC infection was present in all three patients described here, whereas in ICL, Cryptococcus and mycobacterial tuberculosis are most common infections, and only a few cases of MAC infection have been reported [31, 32, 35].

The pathogenesis of primary selective IgM deficiency is unknown; a number of mechanisms have been suggested [21, $22,24]$. However, it appears that significant $T$ cell deficiency with or without NK cell deficiency may contribute to susceptibility of patients with selective IgM deficiency to MAC infections. Furthermore, severity of T cell functional deficiency, including IFN- $\gamma$ secretion, and severity of NK cell functional defect may predispose to dissemination of MAC infection.

In summary, selective IgM deficiency with MAC infection may represent a distinct entity, which is associated with severe $\mathrm{T}$ cell lymphopenia (predominantly $\mathrm{CD} 4+\mathrm{T}$ cells) and decreased IFN- $\gamma$ production. Dendritic cell functions, especially IL-12 production and IL-12R expression remain to be analyzed.

\section{ACKNOWLEDGEMENT}

None declared.

\section{CONFLICT OF INTEREST}

None declared.

\section{REFERENCES}

[1] Cassidy JT, Nordby GL. Human serum immunoglobulin concentrations: prevalence of immunoglobulin deficiencies. J Allergy Clin Immunol 1975; 55: 35-48.

[2] Faulk WP, Kiyasu WS, Cooper MD, et al. Deficiency of IgM. Pediatrics 1971; 47: 399-404.

[3] Hobbs JR, Milner RD, Watt PJ. Gamma-M deficiency predisposing to meningococcal septicaemia. Br Med J 1967; 4: 583-6.

[4] Ross IN, Thompson RA. Severe selective IgM deficiency. J Clin Pathol 1976; 29: 773-7.

[5] Hong R, Gupta S. Selective immunoglobulin M deficiency in an adult with Streptococcus pneumoniae sepsis and invasive aspergillosis. J Investig Allergol Clin Immunol 2008; 18: 214-8. 
[6] Vogelzang NJ, Corwin H, Finlay JL, et al. Clear cell sarcoma and selective IgM deficiency: a case report. Cancer 1982; 49: 234-8.

[7] Saini S, Dettore AJ, Bhambhani KJ, et al. IgM deficiency in CD30+ cutaneous lymphoproliferative disorder. J Pediatr Hematol Oncol 2011; 33:156-9.

[8] Ozawa T, Kondo N, Motoyoshi F, et al. Preferential damage to IgM production by ultraviolet B in the cells of patients with Bloom's syndrome. Scand J Immunol 1993; 38: 225-32.

[9] Kondo N, Ozawa T, Kato Y, et al. Reduced secreted mu mRNA synthesis in selective IgM deficiency of Bloom's syndrome. Clin Exp Immunol 1992; 88: 35-40.

[10] Takeuchi T, Nakagawa T, Maeda Y, et al. Functional defect of B lymphocytes in a patient with selective IgM deficiency associated with systemic lupus erythematosus. Autoimmunity 2001; 34: 115-22.

[11] Antar M, Lamarche J, Peguero A, et al. A case of selective immunoglobulin $\mathrm{M}$ deficiency and autoimmune glomerulonephritis. Clin Exp Nephrol 2008; 12:300-4.

[12] Cunningham-Rundles C. Autoimmunity in primary immune deficiency: taking lessons from our patients. Clin Exp Immunol 2011; 164 (Suppl 2): 6-11.

[13] Arason GJ, Jorgensen GH, Ludviksson BR. Primary immunodeficiency and autoimmunity: lessons from human diseases. Scand J Immunol 2010; 71: 317-28.

[14] Ehrenstein MR, Cook HT, Neuberger MS. Deficiency in serum immunoglobulin (Ig)M predisposes to development of IgG autoantibodies. J Exp Med 2000; 191: 1253-8.

[15] Yel L, Ramanuja S, Gupta S. Clinical and immunological features in IgM deficiency. Int Arch Allergy Immunol 2009; 150: 291-8.

[16] Al-Muhsen S, Casanova JL. The genetic heterogeneity of mendelian susceptibility to mycobacterial disease. J Allergy Clin Immunol 2008; 122: 1043-51.

[17] Qu HQ, Fisher HSP, McCormick JB. Molecular immunity to mycobacterial: knowledge from the mutation and phenotype spectrum analysis of Mendelian susceptibility to mycobacterial diseases. Int J Infect Dis 2011; 15: 305-13.

[18] Safdar A, Armstrong D, Murray HW. A novel defect in interferongamma secretion in patients with refractory nontuberculous pulmonary mycobacteriosis. Ann Intern Med 2003; 138: 521.

[19] Hwang JH, Koh WJ, Kim EJ, et al. Partial interferom-gamma receptor deficiency and non-tuberculous mycobacterial lung disease. Tuberculosis 2006; 86: 382-5.

[20] Francisco LM, Sage PT, Sharpe AH. The PD-1 pathway in tolerance and autoimmunity. Immunol Rev 2010; 236:219-42.
[21] Ohno T, Inaba M, Kuribayashi K, et al. Selective IgM deficiency in adults: phenotypically and functionally altered profiles of peripheral blood lymphocytes. Clin Exp Immunol 1987; 68: 630-7.

[22] De la Concha EG, Garcia RMC, Zabay JM, et al. Functional assessment of $\mathrm{T}$ and $\mathrm{B}$ lymphocytes in patients with selective IgM deficiency. Clin Exp Immunol 1982; 49: 670-6.

[23] Goldstein MF, Goldstein AL, Dunsky EH, et al. Selective IgM immunodeficiency: retrospective analysis of 36 adult patients with review of the literature. Ann Allergy Asthma Immunol 2006; 97: 717-30

[24] Inoue $\mathrm{T}$, Okumura $\mathrm{Y}$, Shirahama $\mathrm{M}$ et al. Selective partial IgM deficiency: functional assessment of $\mathrm{T}$ and $\mathrm{B}$ lymphocytes in vitro. Clin Immunol 1986; 6: 130-5.

[25] Guill MF, Brown DA, Ochs HD, et al. IgM deficiency: clinical spectrum and immunological assessment. Ann Allergy 1989; 62: $547-52$.

[26] Flynn JL, Chan J. Immunology of tuberculosis. Ann Rev Immunol 2001; 19: 93-129.

[27] Vankayalapati R, Wizel B, Samten B, et al. Cytokine profile in immunocompetent persons infected with Mycobacterium avium complex. J Infect Dis 2001; 183: 478-4.

[28] Trinchiari G. Interleukin 12 and the regulation of innate resistance and adaptive immunity. Nat Rev Immunol 2003; 3: 133-46.

[29] Cooper AM, Solache A, Khader SA. Interleukin 12 and tuberculosis: an old story revisited. Curr Opin Immunol 2007; 19:441-7.

[30] Holscher C, Atkinson RA, Arendse B, et al. A protective and agonistic function of IL-12p40 in mycobacterial infection. J Immunol 2001; 167: 6957-66.

[31] Luo L, Li T. Idiopathic CD4 lymphocytopenia and opportunistic infection--an update. FEMS Immunol Med Microbiol 2008; 54(3):283-9.

[32] Trojan T, Collins R, Khan DA. Safety and efficacy of treatment using interleukin-2 in a patient with idiopathic CD4+ lymphopenia and Mycobacterium avium-intracellulare. Clin Exp Immunol 2009; 156: 440-5.

[33] Yamada Y, Okada M, Kamitamari A, et al. Multiple immune abnormalities in a patient with idiopathic CD4+ T-lymphopenia. Int Med 2009; 48: 1967-71.

[34] Ho DD, Cao Y, Zhu T, et al. Idiopathic CD4+ T-lymphopeniaimmunodeficiency without evidence of HIV infection. N Engl J Med 1993: 328: 380-5

[35] Zonios DI, Falloon J, Bennett JE, et al. Idiopathic CD4+ lymphocytopenia: natural history and prognostic factors. Blood 2008;112: 287-94. 